\title{
A ressignificação da Base Nacional Comum Curricular na rede municipal de Juiz de Fora /MG'
}

\author{
The Curricular Common National Base resignification at Juiz de Fora/ \\ MG municipal school system
}

\section{La resignificación de la Base Nacional Común Curricular en la red municipal de Juiz de Fora/MG}

\author{
Denise de Souza Destro² \\ Prefeitura de Juiz de Fora, Professora. \\ https://orcid.org/0000-0002-0372-3138
}

Resumo: 0 objetivo do texto é identificar e refletir acerca da ressignificação da Base Nacional Comum Curricular (BNCC) pela rede pública municipal de ensino de Juiz de Fora/MG, atentando-se para os processos de tradução que ocorrem na reelaboração de suas propostas curriculares. A identificação de demandas curriculares é destacada nesse processo de reelaboração curricular dos diferentes componentes curriculares, criando-se um espaço de visibilidade da cultura e dos processos pedagógicos locais. Defendo que a implementação da BNCC não se dá em simples processo de transferência de um documento nacional para uma realidade específica, pois há diferentes traduções que implicam em articular demandas curriculares locais, possibilitando a produção de outros sentidos para o currículo da rede municipal de Juiz de Fora/MG. A Teoria do Discurso, apropriada pelo campo do currículo, subsidia as discussões empreendidas. 0s caminhos traçados pela Secretaria de Educação de Juiz de Fora/MG sugerem a participação de escolas e seus profissionais no processo de reelaboração curricular, abrangendo os currículos já existentes na rede que, em seu processo de construção, contou com a participação de profissionais da Educação da rede. As demandas curriculares que se destacam nos diferentes grupos disciplinares relacionam-se àqueles referentes ao conhecimento e sua sistematização ao longo da Educação Básica. Assim, há uma pluralidade de sentidos inerente ao processo político de reformulação curricular na rede municipal de Juiz de Fora que viabiliza a contingência das escolhas atribuídas ao processo de ressignificação da BNCC, impedindo, dessa forma, a verticalidade da leitura dessa política educacional de centralidade curricular.

Palavras-chave: BNCC. Currículo. Conhecimento. Demanda curricular.

0 presente trabalho foi realizado com o apoio da Coordenação de Aperfeiçoamento de Pessoal de Nivel Superior - Brasil (CAPES) - código de financiamento 001.

2 Doutora em Educação pelo Programa de Pós-graduação em Educação da Universidade do Estado do Rio de Janeiro; Licenciada em Educação Fisica pela Universidade Federal de Juiz de Fora. 
Abstract: This article aims at identifying and thinking about the Curricular Common National Base (BNCC) resignification at Juiz de Fora/MG municipal public school system, watching over translation processes that take place in curricular proposals re-elaborations. The identification of curricular demands is emphasized in curricular re-elaboration process of diverse curricular components, by creating a spotlighted space for culture and local pedagogical processes. I argue that the BNCC implementation is not applicable through a national document' simple transferring process, placing it at an specific reality, since there are different translations that result in articulating local curricular demands, making possible the production of other different meanings for the Juiz de Fora/MG municipal system. The discourse theory, as appropriate to Curriculum Studies field, supports theoretically the undertaken discussions. The pathways taken by the Juiz de Fora/MG education department indicate the participation of schools and its professionals in the curriculum re-elaboration process, including those curriculums already existing in the school system which had the system education professionals participation in its construction process. The curricular demands that are highlighted in the different disciplinary groups are related to those concerning knowledge and its systematization throughout Basic Education. Thus there is an inherent plurality of meanings in the curricular reformulation political process of Juiz de Fora/MG municipal school system which makes feasible the contingency of the choices assigned to BNCC resignification process, thereby hindering a vertical reading for this educational policy of curricular centrality.

Keywords: BNCC. Curriculum. Knowledge. Curricular demand.

Resumen: El propósito del texto es identificar y reflexionar sobre la resignificación de la Base Nacional Común de Curricular (BNCC) por el sistema de escuelas públicas municipales de Juiz de Fora/ MG, prestando atención a los procesos de traducción que ocurren en la reelaboración de sus propuestas curriculares. La identificación de las demandas curriculares se destaca en el proceso de reelaboración curricular de los diferentes componentes curriculares, creando un espacio para la visibilidad de la cultura y de los procesos pedagógicos locales. Sostengo que la implementación de BNCC no ocurre en un simple proceso de transferencia de un documento nacional a una realidad específica, ya que hay diferentes traducciones que implican articular las demandas curriculares locales, permitiendo la producción de otros significados para el currículum del sistema municipal de Juiz de Fora/MG. La Teoría del Discurso, apropiada por el campo curricular, apoya las discusiones emprendidas. Los caminos trazados por la Secretaría de Educación de Juiz de Fora/MG sugieren la participación de las escuelas y sus profesionales en el proceso de reelaboración curricular, cubriendo los currículos ya existentes en la red que, en su proceso de construcción, contó con la participación de Profesionales de la Educación en la red. Las demandas curriculares que se destacan en los diferentes grupos disciplinarios están relacionadas a aquellos vinculados con el conocimiento y su sistematización a lo largo de la Educación Básica. En este sentido, existe una pluralidad de significados inherentes al proceso político de reforma curricular en la red municipal de Juiz de Fora que hace posible la contingencia de las elecciones 
atribuidas al proceso de resignificación de BNCC, evitando así la verticalidad de leer esta política educativa de centralidad curricular.

Palabras clave: BNCC. Currículum. Conocimiento. Demanda curricular.

Recebido em 16 de setembro de 2020

Aceito em 10 de fevereiro de 2020

\section{INTRODUÇÃO}

A Base Nacional Comum Curricular (BNCC), ${ }^{3}$ homologada em dezembro de 2017 para a Educação Infantil e o Ensino Fundamental e em 2018 para o Ensino Médio, é uma política educacional normativa de centralidade curricular que, ao longo de seu processo de construção, propiciou a articulação de diferentes demandas relacionadas ao conhecimento nos diferentes componentes curriculares (DESTRO, 2019).

A partir de 2018, por meio do Ministério da Educação (MEC) e de parcerias com a União Nacional dos Dirigentes Municipais de Educação (Undime), o Conselho Nacional de Secretários da Educação (Consed) e o setor privado (Fundação Roberto Marinho, Fundação Victor Civita, Instituto Ayrton Senna, Fundação Lemann, Instituto Natura, entre outros), iniciouse o Programa de Apoio à Implementação da BNCC - ProBNCC (BRASLL, 2019), instituído pela Portaria $n^{\circ}$ 331, de 5 de abril de 2018 (BRASIL, 2018). 0 objetivo desse documento é auxiliar estados, municípios e o Distrito Federal na revisão de seus currículos à luz da BNCC. No entanto, com o atual governo, ações mais espećficas acerca da "implementação" da Base, por meio do MEC, não estão sendo assumidas, ficando a cargo, principalmente, da Undime e do setor privado seu desenvolvimento (MACEDO, 2019). Segundo Macedo (2019, p. 44), "[...] - ProBNCC, criado em 2018 para apoiar a implementação da Base, somente foi retomado em início de abril, após pressão das secretarias e conselhos de educação por sua continuidade."

A participação no ProBNCC se deu, inicialmente, no ano de 2018, com a assinatura do Termo de Adesão pelos secretários estaduais de Educação e pelos presidentes das Undimes também estaduais. A participação dos estados nesse programa viabilizou: (1) assistência financeira, via Plano de Ações Articuladas (PAR), às Secretarias de Educação (SEs); (2) formação para as equipes estaduais responsáveis pela implementação da BNCC; e (3) aspectos específicos da reelaboração dos currículos estaduais (por exemplo, financiamento de bolsas para formação das equipes estaduais), bem como materiais de apoio para as

Neste artigo, a BNCC também será denominada de Base. 
discussões (BRASIL, 2019). Além disso, os estados contaram com a disponibilidade de uma plataforma digital, nos mesmos moldes da BNCC, em 2015/2016, para que fossem possibilitadas a participação pública na leitura, críticas e sugestões de seus referenciais curriculares (BRASIL, 2019).

No site do Movimento pela Base, tem-se a notificação de que os referenciais curriculares brasileiros foram finalizados, alinhados à BNCC, após a aprovação dos textos dos estados do Amazonas e do Rio de Janeiro, em outubro de 2019 (BRASIL TEM..., 2019).

Nesse processo de rediscussão curricular ocorrida nos estados, as Secretarias Municipais de Educação foram convidadas a participarem desse momento, de forma a contribuírem com as proposições nas diferentes áreas, assinando um Termo de Adesão. No caso específico do município de Juiz de Fora/MG, esse convite também foi feito, mas por decisão da Secretaria de Educação à época, houve a adesão ao processo político instituído, dispondo-se em auxiliar naquilo que fosse possível, uma vez que a Secretaria de Educação é a representante regional da Undime. No entanto, não houve uma participação efetiva nas discussões do Currículo Referência de Minas Gerias (CRMG) em função de o município de Juiz de Fora/MG ser um sistema educacional e, principalmente, por possuir propostas curriculares construídas com a participação dos profissionais de Educação da rede pública municipal desde 2012.

Entretanto, entendendo o texto da BNCC como normativo e mandatário, a SE de Juiz de Fora/MG, por meio da Subsecretaria de Articulação das Políticas Educacionais (SSAPE) (JUIZ DE FORA, 2019) e seus departamentos - Departamento de Educação Infantil (DEl), Departamento de Ensino Fundamental (DEF) e Departamento de Planejamento e de Formação (DPPF) -, articulou-se para realizar reflexões e discussões das propostas curriculares existentes produzidas pela rede, diante da necessidade imposta via normatização da BNCC e suas implicações na política educacional brasileira. Nesse sentido, o objetivo deste texto é identificar e refletir acerca da ressignificação da BNCC pela rede pública municipal de ensino de Juiz de Fora/MG, atentando-se para os processos de tradução que ocorrem na reelaboração de suas propostas curriculares.

Defendo que a "implementação" da Base não se dá em um simples processo de transferência de um documento nacional para uma realidade específica, pois, nesse percurso, há diferentes traduções que implicam em articular demandas curriculares locais, possibilitando a produção de outros sentidos para as propostas curriculares da rede municipal de ensino de Juiz de Fora/MG. Desse modo, opero com a noção de ressignificação/tradução curricular mediante a política educacional normativa que constitui a BNCC em detrimento do significante "implementação", o qual aponta para uma leitura verticalizada do documento. 
Inicialmente, trago algumas discussões acerca do processo de ressignificação/ tradução da BNCC, dialogando com autores do campo do currículo. Posteriormente apresento brevemente como se constituiu o trabalho desenvolvido pela rede pública municipal de Juiz de Fora/MG no tocante à organização para as discussões das propostas curriculares locais e a BNCC. Em seguida, discuto as experiências de ressignificação/tradução pelos grupos da Educação Infantil, da Educação Física, da Matemática e da História e, por fim, tem-se algumas de minhas impressões acerca do processo instituído.

\section{A IMPOSSIBILIDADE DE UMA LEITURA UERTICALIZADA DA BNCC E O PROCESSO DE TRADUÇÃO CURRICULAR}

As produções curriculares têm perpassado as diferentes políticas educacionais no Brasil. 0 discurso acerca da necessidade de mudanças nos currículos para a melhora na qualidade da Educação é premente, reforçando a noção de que os problemas educacionais estão diretamente ligados à política curricular, a qual engloba tanto a formação inicial e continuada dos professores quanto o seu fazer pedagógico.

Produções curriculares em nível nacional, como a BNCC, tentam normatizar conhecimentos, metodologias e avaliações, produzindo sentidos para o processo de ensino e de aprendizagem a todas as localidades nacionais e racionalizando, dessa maneira, o processo educativo. Documentos como a Base preconizam determinado projeto social e operam com a significação de um sujeito centrado, cuja educação possibilitará a formação da identidade do povo brasileiro.

Em contraposição a esse pensamento, concordo com Cunha e Costa (2019, p. 147) ao afirmarem, com base nos registros teóricos pós-estruturais, a necessidade de se "[...] pensar a educação como relação imprevisível, uma prática cujo resultado jamais pode ser conhecido em totalidade ou referido a um sujeito pleno em consciência no e para o mundo." São sempre apostas no que pode vir a ser e não se tem certezas de que se consolidarão no âmbito escolar e na vida futuros de nossos discentes.

A BNCC, nesse contexto, tenta normatizar aquilo que deve ser ensinado e aprendido no espaço da escola, e Lopes (2015, p. 118) afirma que essa normatividade curricular, em uma perspectiva instrumental, acaba sendo significada como “[...] um conjunto de regras de como agir na prática curricular. Nesse sentido, a Base se conecta ao conhecimento que deve ser ministrado nas escolas, em uma tentativa de controle curricular, dando continuidade naquilo que se vem denominando sua implementação'." 
Ao estabelecer um determinado conhecimento como o conhecimento "verdadeiro" a que todos os alunos têm o direito de ter acesso, a Base afasta "os conhecimentos particulares", na tentativa de anulá-los, mesmo que, em seu texto, aponte para a inserção, nas reformulações curriculares, de conhecimentos referentes à diversidade cultural local. Sobre isso, Lopes (2017, p. 116) afirma que a BNCC opera com a “[...] intenção de que seja possível definir o que é essencial a todos, independentemente das condições de existência de construção curricular", sem admitir as contingencialidades da vida escolar e das muitas possibilidades de se estabelecer o que ensinar. Desse modo, o texto da BNCC discorre sobre os conhecimentos válidos como direito de todos, porém não se associa ao direito de se poder escolher esses conhecimentos (LOPES, 2017), isso tanto no que diz respeito aos estudantes quanto aos professores, coordenadores e diretores das escolas.

Compreender que a normatização expressa pelo texto da Base não encerra a luta política em torno dos currículos e do fazer pedagógico nas escolas (LOPES, 2019; MACED0, 2019) torna-se importante. É necessário salientar, inclusive, que essa normatividade não cessa também as contingencialidades das diferentes regiões do país, os conflitos e os antagonismos que perpassam as políticas educacionais locais (LOPES, 2019).

Desse modo, opero com o entendimento de que a sistematização de uma BNCC proporciona disputas político-discursivas em torno da produção curricular, incrementadas pelas discussões acerca do conhecimento sistematizado ao longo da Educação Básica nos diferentes componentes curriculares (DESTRO, 2019).

0 discurso que o MEC assume é de que a Base não é currículo e, assim, coloca sobre estados e municípios, bem como suas escolas e seus professores, a responsabilidade pela elaboração de seus textos curriculares alinhados à BNCC. Aí se tem uma controvérsia discursiva, pois a BNCC é a referência para as reformulações curriculares, imputando às escolas o papel por sua implementação. Reforça-se, assim, a polarização curricular: de um lado, os documentos "oficiais" e, de outro, a escola, local de implementação desses textos curriculares, sobrepujando o espaço escolar como produtor também de currículo (MACEDO, 2019).

Em contrapartida, é importante destacar que não opero com esse binarismo texto e prática - e muito menos com a retomada da disputa cultural entre o global versus o local e vice-versa. Trata-se de compreender, no entanto, que, no processo de construção curricular, não há lugar para binarismos, e sim que tanto a prática quanto o texto curricular são constituintes da política em torno de qualquer decisão curricular (LOPES, 2015), ou seja, "[...] propostas e práticas não se separam, mesmo quando as enunciamos como tais, e fazem com que se tenha o currículo como um campo de produção de significados em diferentes contextos." (LOPES, 2010, p. 32). 
Além disso, é importante destacar que o processo de construção de textos curriculares não é desvinculado das relações de poder instituídas, haja vista que as possibilidades de escolha se dão "[...] em um terreno indecidivel, implicando sempre a exclusão de outras possibilidades, muitas delas impossíveis de serem nomeadas." (LOPES, 2015, p. १23). Desse modo, a produção curricular pode ser compreendida como uma prática articulatória cujos sentidos são sempre negociáveis por meio de diferentes demandas (LACLAU, 2011). Ademais, os textos curriculares estão sempre sujeitos a diferentes interpretações, sendo ressignificados e traduzidos (LOPES, 2019).

Entender os textos curriculares como passiveis de ressignificação/tradução nos possibilita apreender a impossibilidade de uma leitura verticalizada da Base, tantos nas esferas estaduais quanto nas municipais, nas instituições privadas e nas escolas. 0 texto da BNCC não consegue, por mais que tente seduzir o leitor a isso, proporcionar uma leitura única de seus pressupostos como a verdade textual curricular, sistematizando um dado conhecimento tido como universal. Nesse sentido, a noção de tradução serve para confrontar a normatividade (CUNHA; COSTA, 2019) posta pela Base, pois que a tradução nunca será absoluta, isto é, haverá sempre uma multiplicidade de sentidos que serão produzidos em sua leitura e das muitas associações que podem ser possibilitadas (DERRIDA, 2002).

Soma-se a isso a noção de impossibilidade de o currículo ser o mesmo para todos, haja vista as muitas traduções/ressignificações que serão conferidas à leitura da BNCC nos processos de reelaboração curricular locais. Sobre isso, Siscar (2012, p. 20) reitera que, para Derrida,

[...] a leitura não deve ter como ilusão o respeito do conteúdo dito intencional de um texto, ainda que um domínio instrumental do que se considera o conteúdo (histórico, convencional etc.) de tal texto seja fundamental: não há intencionalidade do texto, conteúdo unívoco daquilo que ele quer dizer.

Operar com a noção de que a Base possui um texto normativo que pode ser lido por todos da mesma forma é descaracterizar a potencialidade humana na produção de sentidos. Trazendo para o campo das políticas curriculares, afirmo que toda leitura curricular pode ser pensada como uma tradução que é, ao mesmo tempo, necessária e impossível; no entanto, sua leitura se caracteriza como uma univocidade impossível (DERRIDA, 2002). A tradução pode ser considerada, então, como uma interpretação não literal, impossivel de dar conta da intencionalidade do texto escrito.

Discorrendo sobre o sentido de um texto, Siscar (2012, p. 20) salienta que "[...] toda leitura pode ser considerada como uma produção de sentido" e que a desconstrução também "[...] é um gesto produtor de sentido, mas uma produção que tem como uma particularidade 
a ativação ou a aceleração do movimento conflitante no qual o próprio texto e sua leitura estão implicados."

Se partirmos da noção de currículo como uma tradução, podemos inferir que, ao se ler a BNCC, os atores sociais envolvidos no processo de ressignificação desse documento em suas redes de ensino farão a tradução do que está posto como discurso. Nessa lógica, podemos pensar esses mesmos atores como tradutores curriculares e que isso demanda contingencialidades. Segundo Derrida (2002, p. 40, grifo do autor):

\footnotetext{
[...] todo tradutor está em posição de falar da tradução, em um lugar que não é nada menos que segundo ou secundário. Pois se a estrutura do original é marcada pela exigência de ser traduzido, é que, fazendo disso a lei, o original começa por endividar-se também em relação ao tradutor. 0 original é o primeiro devedor, o primeiro demandador, ele começa por faltar - e por lastimar após a tradução.
}

Dessa forma, podemos nos ater à noção de currículo como tradução e que tanto a BNCC quanto as propostas curriculares reelaboradas a partir desse documento federal podem ser pensadas como "[...] estruturas discursivas provisórias emanadas de alguma ilusão de estabilidade do sentido ao conjecturarem a educação - que entendemos ser impossível - como algo dominável, racionalizável." (CUNHA; COSTA, 2019, p. 145).

0 texto da BNCC não é transparente... É opaco. Em uma leitura rápida, o discurso da Base pode seduzir muitos daqueles que estão imersos nas escolas, reforçando que os males da Educação podem ser resolvidos a partir de reformulações curriculares e da sistematização dos conhecimentos por ano escolar que não estão sendo ministrados aos estudantes como direito. Entretanto, em uma leitura mais atenta, utilizando-se lentes que ampliem as letras, frases e associações, visualizamos discursos que tentam controlar aquilo que é incontrolável: a dinâmica escolar e as relações didático-pedagógicas ali instituídas. Cunha e Costa (2019, p. 160) afirmam que "[...] se há uma educação, se ela de fato acontece, nós não a controlamos como a um resultado daquilo que seja possível enunciar." Dessa forma, a Base já está posta como uma política curricular falivel e que responsabiliza ainda mais os docentes e suas práticas pedagógicas pelos rumos que a Educação brasileira está tomando.

A BNCC, assim, não traz $\underline{a}$ verdade do currículo nem muito menos aponta $o$ único caminho a ser seguido. É uma possibilidade, entre várias, produzida em meio a disputas por hegemonia e atravessada por controvérsias tanto educacionais quanto políticas. Isto posto, não existe a verdade curricular. A política curricular é luta por significação, é prática discursiva, é luta por hegemonia (LOPES; MACED0, 2011). 
Partir do pressuposto de currículo como tradução é compreender que, no processo de reelaboração de textos curriculares locais à luz da BNCC, haverá negociação de diferentes demandas político-discursivas, produzindo diferentes sentidos aos seus textos "finais". Dessa forma, no processo de ressignificação das propostas curriculares da rede municipal de Juiz de Fora/MG perante o documento normativo que é a BNCC, penso que haverá sempre negociação, seja pela sistematização dos conhecimentos ao longo do Ensino Fundamental, seja pelos direcionamentos didático-metodológicos e avaliativos pelos quais os grupos disciplinares optarão, além das devolutivas das escolas, englobando, dessa forma, - fazer pedagógico dos professores com seus estudantes. Nesse sentido, concordo com Lopes (2019) quando enfatiza a necessidade de o currículo fazer sentido e ser elaborado/ discutido/produzido contextualmente, atendendo as diferentes demandas e necessidades locais, que não se constituem como homogêneas.

\section{OS TEXTOS CURRICULARES DE JUIZ DE FORA E A BNCC}

Em 2018, a SE da rede pública municipal de Juiz de Fora foi convidada a participar do processo de reelaboração do currículo do estado de Minas Gerais. Apesar de a SE assinar o Termo de Adesão, não houve uma participação efetiva da rede na reformulação curricular de Minas Gerais. A justificativa se pautou, especificamente, por Juiz de Fora ser um sistema de ensino e, principalmente, por possuir propostas curriculares para a Educação Infantil, para - Ensino Fundamental e Educação de Jovens e Adultos (EJA) desde 2012. Essas propostas curriculares foram produzidas no âmbito da SE de Juiz de Fora, contando com profissionais de Educação da rede municipal (professores, coordenadores pedagógicos, diretores e técnicos da SE) e de professores da Universidade Federal de Juiz de Fora (UFJF), que trabalhavam em diferentes cursos de licenciatura, culminando com um seminário que deu origem aos textos curriculares oficiais até então. Desse modo, se a SE aderisse ao CRMG, o município de Juiz de Fora teria que seguir o currículo estadual, descaracterizando, assim, as propostas curriculares locais com suas demandas também locais.

Apesar de não participar da discussão e elaboração do CRMG, a SE está participando da "implementação" da BNCC instaurada pelo MEC, aderindo aos processos de formação e aos itinerários avaliativos de Minas Gerais. Os itinerários avaliativos se caracterizam como um conjunto de ações disponiveis em uma plataforma digital a qual analisa dados das escolas, auxiliando na elaboração de seus planos de ação (ITINERÁRIOS..., 2019), de forma a fomentar a reelaboração dos Projetos Políticos Pedagógicos (PPPs) das escolas. No que concerne ao processo de formação, a SE disponibilizou espaços para que as formações acerca do CRMG possam ser realizadas abarcando os municípios da região ao longo de 2020. 
Concomitantemente a esse momento, no início de 2019, a SE decidiu rediscutir suas propostas curriculares em meio à política educacional em torno da BNCC e seus desdobramentos (como avaliações, livro didático e formação continuada), promovendo reflexões e discussões em cada componente curricular. Partindo das propostas curriculares oficiais da rede pública municipal de Juiz de Fora/MG, os diferentes grupos por componente curricular, Educação de Jovens e Adultos (EJA) e Educação Infantil foram orientados a fazerem leituras de suas respectivas propostas e da BNCC, visando, em um primeiro momento, traçar as aproximações e os distanciamentos entre esses dois documentos. 0 CRMG foi agregado a esse momento em função de os estudantes da rede pública municipal participarem de avaliações, como o Programa de Avaliação da Alfabetização (Proalfa), ${ }^{4}$ o qual será restruturado a partir do CRMG. Posteriormente, objetivou-se construir proposições curriculares por componente, para a Educação Infantil e para a EJA a fim de serem debatidas com os profissionais de Educação da rede municipal nas escolas.

A dinâmica de discussão das propostas curriculares foi organizada separadamente por cada grupo representante dos componentes curriculares/etapa (Educação Infantil; Língua Portuguesa; Língua Inglesa; Arte; Educação Fisica; Matemática; Ciências; Geografia; História, EJA e Tecnologias), estipulando-se um encontro semanal no primeiro semestre de 2019. Foram convidados diretores, coordenadores pedagógicos e professores atuantes nas escolas para comporem os grupos de trabalho por componente curricular juntamente com os técnicos da SE, que também são professores da rede, mas que estão atuando na Secretaria atualmente. A importância da participação dos profissionais de Educação da rede se dá, por meio do discurso da SE, de forma a produzir um currículo que seja representativo do trabalho pedagógico que vem sendo desenvolvido nas escolas do município com suas demandas específicas.

Os grupos de trabalho, no entanto, formaram-se com pouca participação docente e de gestores escolares em função das muitas atribuições geradas nas/pelas escolas, as quais inviabilizam a participação efetiva nos encontros. Diante de tal fato, a SE pensou em uma forma de as proposições curriculares reelaboradas pelas equipes chegarem às escolas para serem discutidas em reuniões pedagógicas que acontecem mensalmente ou em outros momentos. Assim, criou-se um ambiente virtual na plataforma Moodle, que já vem sendo utilizada pelos diretores e coordenadores, para disponibilizar os documentos produzidos e espaços para que as "escolas" (lê-se professores, coordenadores e diretores) possam contribuir com suas sugestões e fazerem suas críticas. Dessa forma, abriu-se a oportunidade de participação dos profissionais de Educação para que tecessem suas contribuições, críticas e sugestões aos textos por componente curricular, na forma de uma 
consulta prévia ao texto curricular final. No que diz respeito à consulta pública, à época da BNCC, Ribeiro e Craveiro (2017, p. 57) salientam que é uma “[...] estratégia de legitimação. A partir dela, se ganha adesão, configurando um discurso de respeito à participação e à diversidade." Nesse sentido, vislumbrando a importância da participação dos profissionais da Educação da rede pública municipal de Juiz de Fora, a SE optou pela utilização da plataforma Moodle na tentativa de abarcar o maior número de contribuições, sugestões e críticas às propostas curriculares da rede.

A participação da equipe gestora, bem como dos professores da escola, é assumida pela SE como essencial, pois entende-se que são esses os atores sociais que vivem o fazer pedagógico diariamente, que lidam com a imprevisibilidade do ato educativo e, portanto, são imprescindíveis no fazer curricular, além de oportunizar a elaboração de um documento participativo, que tente abarcar as diferentes demandas das escolas. Sobre isso, Lopes (2015, p. 460) afirma que refletir e debater "[...] contextualmente o que está sendo realizado nas escolas e o que estamos valorizando pode ser uma aposta mais produtiva para as políticas de currículo" do que um documento a nível nacional, como são a BNCC e o CRMG.

Apesar de essa tentativa ser impossível, ou seja, existir um documento curricular que atenda a todas as demandas das regiões mesmo que localmente, produzir textos curriculares a nível municipal me parece ser possivel e mais produtivo, na medida em que realidades locais mais próximas podem apresentar demandas mais equivalentes se comparadas a localidades dispersas pelo Brasil.

Foi pedido às equipes por componente curricular, da EJA e da Educação Infantil que fizessem um documento comparativo entre as proposições dos textos curriculares da rede, o da BNCC e o do CRMG para, a partir dessa comparação, produzir-se parte do texto curricular por componente, Etapa e Modalidade. Uma angústia presente em todos os grupos de trabalho se deu com relação à normatividade da BNCC, haja vista a "impossibilidade" de retirada de conhecimentos trazidos pelo documento, na forma de Unidades Temáticas e Objetos de Conhecimento. As equipes passaram a perceber então que a BNCC adensa as propostas curriculares com conhecimentos compreendidos como essenciais a que todos os discentes devem ter acesso, e que aqueles referentes às realidades locais são os denominados de parte diversificada. Assim, as equipes questionaram a própria sistematização desses conhecimentos ao longo dos anos escolares, notando a supressão de saberes considerados localmente como importantes, tais como as culturas afro-brasileiras e indígenas, as questões de gênero e sexualidade, a história do Brasil, entre outros, além de alguns conhecimentos terem sido deslocados para outros anos escolares.

Como o processo de reelaboração da proposta curricular da rede municipal de Juiz de Fora/MG está em fase de finalização, há de se destacar que as discussões inicias 
para a elaboração dos textos preliminares ocorreram independentes, ou seja, cada equipe por componente curricular, Educação Infantil e EJA desenvolveu seu trabalho independentemente das demais, sem se ater à lógica por área sistematizada pela BNCC. Isso me parece ocorrer em função de o currículo da rede ser configurado por componentes curriculares, e não por área. A respeito da sistematização por área pela BNCC, Lopes (2019, p. 63) salienta que esse tipo de organização não elimina o registro disciplinar e que "[...] alterar a organização curricular implica modificar identificações docentes." Isso se torna relevante na medida em que a BNCC opera com a área de Linguagens, por exemplo, a qual é composta pela Língua Portuguesa, Língua Inglesa, Arte e Educação Física, sendo que o elo integrador entre os componentes é a linguagem. No caso da Educação Física e da Arte, especificamente, o pertencimento à área de Linguagens não é consensual, provocando debates no campo (DESTRO, 2019).

No próximo item, apresento algumas das ressignificações/traduções concernentes à BNCC realizadas pelos grupos que integram alguns componentes curriculares e da Educação Infantil da SE de Juiz de Fora/MG.

\section{AS RESSIGNFICAÇÕES/TRADUÇÕES DA BNCC PELA REDE PÚBLICA MUNICIPAL DE JUIZ DE FORA/MG}

As ressignificações da BNCC estão, continuamente, sendo realizadas em todo o país. Tanto no processo de reelaboração dos textos curriculares estaduais quanto na política de produção dos livros didáticos e, agora, nos itinerários formativos nos estados, elas têm propiciado processos de tradução do documento federal, abrangendo uma multiplicidade de sentidos. Assim, neste tópico, opto por apresentar as ressignificações/traduções de trabalhos desenvolvidos por três equipes de diferentes componentes curriculares e uma etapa da Educação Básica da rede pública municipal de ensino de Juiz de Fora/MG no processo de rediscussão de suas propostas curriculares locais a partir da BNCC. Tomo os trabalhos desenvolvidos pelas equipes referentes à Educação Infantil, Educação Física, Matemática e História ${ }^{5}$ por apresentarem experiências distintas no fazer curricular nesse processo, as quais potencializam o debate acerca da ressignificação/tradução da BNCC em contextos locais e em registros disciplinares distintos. 
A identificação e reflexão acerca das discussões desses componentes curriculares e da Educação Infantil foram organizadas da seguinte maneira: (1) leitura do texto preliminar de cada um; (2) leitura das devolutivas das escolas acerca desses textos; (3) anotações das apresentações do texto curricular nas reuniões de coordenadores; (4) anotações durante as reuniões das equipes dos três componentes curriculares e da Educação Infantil a respeito da discussão do trabalho que estava sendo realizado; e (5) conversas com os membros das equipes.

A equipe responsável pelas discussões da Educação Infantil não apresentou uma nova proposição para discussão com os profissionais de Educação da rede, pois a proposta curricular dessa etapa, que é organizada em dois cadernos (JUIZ DE FORA, 2010, 2011), foi produzida a partir de ordenamentos legais da época, mais especificamente a partir das Diretrizes Curriculares Nacionais para a Educação Infantil (DCNEI) (BRASIL, 2010) e do Referencial Curricular Nacional para a Educação Infantil (RCNEI) (BRASIL, 1998).

Desse modo, ao fazer o comparativo com a BNCC, a equipe da Educação Infantil percebeu que as orientações trazidas pelo documento federal complementam o currículo já existente da rede em alguns pontos específicos, como: a organização pela faixa etária bebês (de 0 a 1 ano e 6 meses), crianças bem pequenas (de 1 ano e 7 meses a 3 anos e 11 meses) e crianças pequenas (de 4 a 5 anos) -, os campos de experiências (" 0 eu, o outros e o nós"; "Corpo, gestos e movimentos"; "Traços, sons, cores e formas"; "Escuta, fala, pensamento e imaginação"; "Espaços, tempos, quantidades, relações e transformações"), a adequação aos objetivos de aprendizagem e desenvolvimento e as discussões acerca do processo de transição da Educação Infantil para os anos iniciais do Ensino Fundamental.

A equipe apontou certo incômodo com relação aos objetivos de aprendizagem e desenvolvimento estarem relacionados a códigos alfanuméricos, pois entendem que isso pode propiciar uma leitura linear dos mesmos, fazendo com que os professores trabalhem de forma "isolada" e sequencial, sem se aterem ao todo do processo educativo dessa etapa específica. No entanto, há de se destacar que todo texto é passível de diferentes leituras e que aqueles que decidem/escrevem um texto curricular não têm controle sobre essas leituras, e quem o lê também passa por um processo de tradução textual. Assim, de acordo com Lopes, Cunha e Costa (2013, p. 401, grifo do autor), a tradução "[...] impõe limites instransponíveis, que impossibilitam o tradutor/agente/sujeito a manutenção e a reprodução de uma suposta intenção 'original' do texto."

As devolutivas das escolas apresentam concordância com a proposição de se manter o texto curricular da Educação Infantil disponível em dois cadernos, porém a equipe escreveu um texto que trará as justificativas de tal manutenção. Além disso, a equipe da Educação Infantil tem a intenção de produzir um terceiro caderno, valorizando e dando visibilidade às práticas desenvolvidas pelas creches e pelas escolas da rede, em conformidade 
com o seu texto curricular, destacando a pedagogia de projetos como orientação do trabalho pedagógico para essa etapa da Educação Básica.

A equipe responsável pelas discussões acerca da Educação Fisica partiu de um currículo produzido nos anos 2000 para fazer o comparativo com a BNCC. Esse componente curricular é o único da rede que não apresentou uma reformulação no ano de $2012^{6}$ e, por esse motivo, não está disponibilizado no formato digital, no site da Prefeitura, e sim somente na versão impressa. 0 grupo considerou que muitas questões dessa proposta curricular precisavam ser rediscutidas e reelaboradas a partir dos muitos estudos que a área tem produzido na atualidade e da própria prática pedagógica da rede.

Assim, o comparativo enviado às escolas se pautou na apresentação dos princípios didático-metodológicos, dos eixos temáticos, da sistematização do conhecimento da Educação Infantil ao $9^{\circ}$ ano do Ensino Fundamental e da avaliação nos dois documentos (proposta da rede e BNCC). No entanto, a proposição que foi para as escolas pautou-se somente na sistematização dos conhecimentos.

A Educação Infantil na BNCC não possui direcionamentos específicos para o trabalho com a Educação Física, muito embora os campos de experiências possibilitem essa articulação. Porém, na rede pública municipal de Juiz de Fora/MG, a Educação Física faz parte da Educação Infantil e dos anos iniciais do Ensino Fundamental, sendo ministrada por licenciados em Educação Física. Assim, o grupo optou por estabelecer relações entre o que a Educação Física pode oferecer como componente curricular e seus conhecimentos específicos para as crianças da Educação Infantil $\left(1^{\circ}\right.$ e $2^{\circ}$ períodos), ${ }^{7}$ em diálogo com o documento que a equipe da Educação Infantil estava discutindo. A equipe de Educação Fisica ressignificou a BNCC da Educação Infantil para além do campo de experiências "Corpo, gestos e movimentos", o que, em um primeiro momento, poderia supor aí uma sistematização de seu conhecimento. A tradução que o grupo fez perpassa esse campo, sistematizando, de forma geral, possibilidades pedagógicas em todos os campos de experiências: " 0 eu, o outro e o nós", “Corpo, gestos e movimentos", "Traços, sons, cores e formas", “Escuta, fala, pensamento e imaginação" e "Espaços, tempos, quantidades, relações e transformações".

Entendo que essa organização da Educação Física para a Educação Infantil pode ser pensada por aquilo que Derrida chama de desconstrução. Nas palavras de Strathern (2002, p. 42), a desconstrução derridiana equivale ao desmonte daquilo “[...] que já foi juntado implicitamente em um texto. A monumental autoridade de um texto é desarmada. Em vez

6 Na época, houve um grupo de professores de Educação Fisica que também discutiu o currículo de 2000. No entanto, as orientações desse mesmo grupo se pautaram na manutenção do documento, haja vista o entendimento de que ele ainda representava as práticas pedagógicas do componente. 0 grupo apontou alguns aspectos que deveriam ser acrescentados no documento; no entanto, ele não foi finalizado.

7 Não há um trabalho específico da Educação Fisica nas creches de Juiz de Fora/MG. 
de um significado, ele assume vários." Dessa forma, a Educação Física na rede pública municipal de ensino de Juiz de Fora ressignifica a BNCC, extrapolando a lógica de seu texto e potencializando, assim, sua atuação nessa etapa da Educação Básica.

Outro aspecto a ser destacado faz referência à demanda da equipe da Educação Física no que diz respeito a uma prévia sistematização do conhecimento para os anos escolares do Ensino Fundamental | e II. Isso se deu em função de alguns ordenamentos da BNCC serem definidos de forma diferente daquela trazida pelo texto curricular da rede. Dentre eles, destaco a forma como a Base classifica os Esportes (marca; precisão; técnicocombinatório; rede/quadra dividida ou parede de rebote; campo e taco; invasão ou territorial; combate); a retirada da sistematização das Brincadeiras e Jogos para todos os anos escolares; e a inserção de Lutas (a partir do $3^{\circ}$ ano) e Práticas Corporais de Aventura (a partir do $6^{\circ}$ ano) como Unidades Temáticas da Educação Fisica. Isso levou o grupo a refletir acerca dessa sistematização do conhecimento, principalmente porque o texto curricular da rede não opera com Lutas, mas sim com a Capoeira, pois, na época em que o currículo foi produzido, essa foi a prática corporal mais encontrada e praticada pelos alunos da rede. ${ }^{8}$

Incomodada também pela sistematização apresentada pela BNCC, a equipe da Educação Física optou por: (1) expor todos os conhecimentos que esse documento nacional apresenta; (2) modificar o entendimento a respeito da Unidade Temática Ginásticas; (3) inserir as Práticas Circenses nos anos iniciais do Ensino Fundamental; (4) apresentar as Lutas para todos os anos escolares (da Educação Infantil ao $9^{\circ}$ ano); e (5) modificar algumas das habilidades propostas pela Base, acrescentando outras que o documento não contempla.

Na devolutiva das escolas, não houve apontamentos discordantes a respeito da sistematização do conhecimento. A equipe da Educação Física optou por não fechar o texto curricular do componente com um único direcionamento didático-pedagógico, compreendendo as inúmeras formas de trabalho existentes na rede. Essa postura não é a de assumir uma neutralidade pedagógica, mas sim possibilitar que o fazer pedagógico da rede seja plural, como o é em todas as áreas, e que não há como controlar tais práticas.

Já no que concerne à equipe da área de Matemática, os professores envolvidos nas discussões consideraram que o texto curricular da rede apresenta algumas lacunas com relação a alguns conhecimentos, sem aprofundamentos que seriam interessantes de serem trazidos em aulas, tais como a compreensão dos diversos significados que envolvem as operações aritméticas tão presentes em contextos sociais e a falta de diálogo com as demais áreas de conhecimento e com os temas transversais que os Parâmetros Curriculares

8 No currículo da Educação Fisica (JUIZ DE FORA, 2000), para a sistematização dos conhecimentos para a Educação Infantil e o Ensino Fundamental, foi feita uma pesquisa nas comunidades e com os alunos para identificar as práticas corporais mais praticadas nas localidades atendidas pelas escolas municipais. A partir dessa identificação, sistematizou-se os conhecimentos do componente curricular em questão em Jogos, Dança, Esportes, Ginástica e Capoeira (DESTRO, 2004). 
Nacionais (PCN) preconizavam à época. Uma hipótese para isso seria propiciar mais autonomia aos professores no trato com os conhecimentos do componente curricular Matemática. 0 grupo responsável por esse componente entendeu que a BNCC, em alguns momentos, apresenta os conhecimentos de forma generalizada e, em outros, traz certo detalhamento. Além disso, o grupo apontou que a proposta da rede apresenta algumas grandes temáticas discutidas em 2012, porém não dialoga com atuais temáticas que a Sociedade Brasileira de Matemática preconiza, como Tecnologia, Educação Financeira, entre outras. No documento comparativo que foi enviado às escolas, a equipe de Matemática optou por sistematizar os pontos de aproximação e de distanciamento entre os dois documentos (proposta de Matemática e BNCC) sem, entretanto, explicitar uma reflexão acerca do que estava sendo posto a respeito da Educação Matemática.

Após a devolutiva das escolas acerca da proposição de Matemática, a equipe manteve os direcionamentos da Base, enxertando lacunas que foram percebidas no documento federal a partir de alguns pontos do currículo da rede de 2012. Isso gerou um documento extenso, porém sem a pretensão de ser um receituário e com a intenção de se pensar para além do que estiver posto na proposta curricular. Como exemplo, tem-se o "pensar sobre as operações aritméticas", sendo necessário que elas sejam refletidas em todas as suas estruturas, em todos os seus significados. No entanto, a equipe teme que esse pensar além do que estiver posto não seja compreendido pelos docentes e, por esse motivo, optou por deixar explicitados e detalhados os conhecimentos matemáticos, muito embora receie que o texto curricular da rede seja significado como um texto engessado. Mais uma vez, tem-se o entendimento de controle da leitura do outro no processo de ressignificação curricular. Tanto a equipe responsável pela reelaboração curricular a partir da BNCC quanto os próprios professores nas escolas são sempre tradutores dos textos curriculares. Nesse sentido, Strathern (2002, p. 37) afirma que "o leitor está livre para adicionar sua própria interpretação, atitude e intenção. As palavras na página - ambíguas por si próprias, são meras caixas de ressonância para a interpretação do leitor."

Nessa perspectiva, Lopes, Cunha e Costa (2013, p. 403, grifo dos autores) salientam que

Reconhecer na tradução a subjetivação pelo outro é acenar para a concepção de que traduzir/escrever/iterar é a possibilidade de acesso de significação mesma da política, do mundo. Toda tradução, portanto, é uma produção original que, ao ser desencadeada, ainda que o tradutor pretenda se reconciliar com um suposto sentido anterior, ela já o corrompeu, cabendo-the à suplementação como sentença final, como a possibilidade de expressão e continuidade. 
A equipe de Matemática entendeu a necessidade de mais tempo para discutir os currículos e ampliar os debates na escola de forma que o texto curricular produzido após essas discussões possa ser significativo do fazer pedagógico docente.

Já o grupo responsável pelo componente curricular História relatou ter passado por grandes dificuldades em produzir o quadro comparativo solicitado pela SE e em formular uma proposição a ser enviada às escolas, porque a lógica do texto curricular de História da rede não segue a linearidade temporal proposta pela BNCC. 0 documento da rede municipal de Juiz de Fora se pauta em três grandes eixos - Conhecimento, Temporalidade e Memória -, e a Base vem trazendo os conhecimentos da área apagando a história pré-colombiana, brasileira, do negro, entre outras.

0 grupo se propôs a "subverter" a BNCC, entendendo ser impossível renunciar aos conhecimentos tão caros à História e se adequar à sistematização trazida pelo documento federal. Entendo que assumir essa postura não é subverter a ordem da BNCC, mas sim se constitui em uma forma de produção curricular que emerge das contradições que o documento do MEC indica. Isto posto, opero com a noção de superação entre o escape e a regulação do texto curricular e com a perspectiva de que ambos se reconfiguram e fazem parte da política curricular (LOPES; CUNHA; COSTA, 2013). Desse modo, penso que o posicionamento da equipe de História pode ser significado como tradução ou ressignificação de um texto "oficial" que não consegue controlar a sua leitura e que causa desconfortos, os quais não são anulados em função da política mandatária. Eles fazem parte dessa mesma política que ecoa nas produções locais. Nesse processo de ressignificação/tradução da BNCC, outros sentidos são dados aos textos curriculares locais, os quais vão muito além da normatividade e da padronização curricular pretendida.

A equipe do componente curricular História assumiu o discurso de que não está abrindo mão do que esteja posto pela BNCC, mas deixou registrada a necessidade de se ampliar o olhar para os vencidos historicamente e para a cultura afro-brasileira na proposição curricular da rede. Para o grupo, dizer NÃO à BNCC, subvertendo seu texto, é valorizar e defender a escola pública e a população afro-brasileira, de forma a contribuir para a formação humana, para a formação para a vida. Esse posicionamento justifica-se como uma política de afirmação da escola pública. Desse modo, podemos inferir que os responsáveis pela rediscussão curricular do componente História realizam uma tradução dos direcionamentos desse componente, apresentando uma possibilidade de trabalho pedagógico entre outras possiveis e inserindo-se na própria dimensão da tradução como reapropriação textual.

Assim, a BNCC é entendida pelo grupo de História como um documento que possibilita repensar o texto curricular da rede pública municipal de Juiz de Fora/MG de forma 
a defendê-lo, possibilitando, inclusive, olhar novamente para ele, refletindo suas possibilidades pedagógicas.

Concordo com Macedo (2019, p. 42) ao mencionar que

[...] toda tradição curricular se dá conta de que o currículo - para ser
currículo - precisa acontecer nas escolas lou nos lugares e tempos em
que acontecem). Em muitas dessas tradições, no entanto, a produção e
a implementação curricular são tomadas como momentos distintos, sendo
este apenas a aplicação - ou a transposição - do que aquele instituiu. Esse
é, sem dúvida, o modelo subjacente à proposta mesma da BNCC, modelo este
tensionado durante o processo.

Desse modo, os textos curriculares produzidos, reelaborados, discutidos e pensados em instâncias locais, como em Secretarias Municipais de Educação e, por conseguinte, nas próprias escolas, são potentes no debate curricular. Apresentar um documento em nível federal, como é a BNCC, não significa que sujeitos em diferentes espaços farão leituras lineares e verticalizadas desse documento. Isso possibilitará o processo de ressignificação/tradução sem, necessariamente, reproduzir o sentido do original que o texto tenta apresentar - se é que ele mesmo pode ser considerado como um texto original. Nesse sentido, Siscar (2012, p. 20), com base em Derrida, afirma que "[...] não há intencionalidade do texto, conteúdo unívoco daquilo que se quer dizer [...] a desconstrução é um gesto produtor de sentido."

0 estudo comparativo entre a proposta da rede municipal de Juiz de Fora e a BNCC, bem como a elaboração de uma proposição curricular para ser encaminhada para debates nas escolas, foram apresentados aos diretores e coordenadores pedagógicos em reuniões específicas. Há de se destacar que essas proposições, basicamente, foram pautadas na sistematização dos conhecimentos por componentes curriculares e na distribuição dos mesmos pelos anos escolares, sem destacar questões como metodologia e avaliação e as relações que se estabelecem entre os componentes e entre as áreas.

Em reunião realizada em fevereiro de 2020 entre os representantes das equipes por componente curricular, da Educação Infantil e a equipe gestora da SE, ficou acertado que a proposição curricular de Juiz de Fora/MG será elaborada em texto único, como feito na BNCC. Foi pedido às equipes para elaborarem textos acerca de suas especificidades pedagógicas, além de manterem a sistematização do conhecimento da forma como foi enviada às escolas, ou seja, por meio da organização em Unidades Temáticas, Objetos de Conhecimento e Habilidades. Houve exceção para Educação Infantil, EJA e História, que irão manter o currículo da rede; Língua Portuguesa, que se organiza em Práticas de Linguagem e 
Campos de Atuação; e Língua Inglesa, que apresenta seus conhecimentos por meio de Eixos e Unidades Temáticas.

As propostas curriculares reformuladas da rede pública municipal de Juiz de Fora/MG estão sendo finalizadas no segundo semestre de 2020, e a SE pretende oferecer aos docentes dos diferentes componentes curriculares cursos de formação continuada, no Cento de Formação do Professor do DPPF.

Para além das traduções feitas pelas equipes instituídas, tem-se as ressignificações/traduções que os professores farão das proposições enviadas às escolas e, com elas, outras ressignificações.

Assim, o currículo é um constante processo de tradução, uma prática discursiva que abrange uma infinidade de possibilidades no fazer pedagógico.

\section{DA RESSIGNIFICAÇÃO/TRADUÇÃO ÀS PRÁTICAS ESCOLARES}

Este texto possibilitou apresentar parte de um processo de ressignificação/ tradução curricular que aconteceu no município de Juiz de Fora/MG a partir da BNCC. Muito embora esse processo não tenha se findado (se é que, em algum momento, as discussões curriculares se findam), alguns apontamentos podem ser feitos.

No trabalho que vem sendo desenvolvido pelos diferentes grupos e, em especial, os destacados aqui, é possível concluir que, mesmo que a BNCC seja sumariamente compreendida como uma política mandatária e que sua "implementação" tenha que acontecer nos espaços escolares, a SE de Juiz de Fora opta por discutir e produzir seus textos curriculares partindo daqueles que foram produzidos em 2012, coletivamente, sem aderir ao CRMG.

Cada equipe, com suas demandas específicas, vem ressignificando/traduzindo a BNCC de diferentes formas e vem produzindo proposições em diálogo com os seus textos curriculares locais e com o trabalho que já vem sendo realizado pela rede municipal de ensino. Assim, na tradução, "[...] a circulação do significante não tem origem nem fim, o processo é incessante." (LOPES; CUNHA; COSTA, 2013, p. 405). Houve "autonomia" na elaboração desses textos curriculares que foram enviados às escolas para serem discutidos pelos profissionais de Educação do município, com possibilidade de esses mesmos profissionais, com o coletivo escolar, fazerem também suas ressignificações/traduções. Autonomia essa que não existe, haja vista que, muito embora as equipes tenham tido liberdade de se reunirem e produzirem o comparativo e a sistematização de seus conhecimentos, outra normatividade é encontrada, isto é, a normatividade do próprio registro disciplinar com seus saberes e tradições. As 
tradições de cada registro disciplinar são trazidas para o processo de elaboração do texto curricular de forma a cercear essa tal "autonomia", impelindo-nos a negociar demandas curriculares.

Assim, os processos de ressignificação/tradução da BNCC realizados no âmbito da rede municipal de Juiz de Fora/MG nos mostram que mesmo um documento mandatário não consegue ser "implementado" da mesma forma que é explicitada em seu texto. Há rupturas com o texto "original", 9 promovendo ressignificações e traduções de todos aqueles que lidam com o fazer pedagógico local. Dessa maneira, a verticalidade da política do texto da BNCC e sua "implementação" jazem sobre a impossibilidade de uma leitura unívoca do documento, pois não escapa aos muitos sentidos produzidos localmente, permitindo outras leituras e significações também no fazer pedagógico.

Vale destacar que essa é a minha tradução do processo instituído pela SE e que tantas outras podem também ser feitas, proporcionando a multiplicidade de sentidos a que estamos imersos no campo da discursividade.

\section{REFERÊNCIAS}

BRASIL. Ministério da Educação. Base Nacional Comum Curricular. Brasilia, DF: Ministério da Educação, 2017. Disponivel em: http://basenacionalcomum.mec.gov.br/images/BNCC_El_EF_110518_versaofinal_site.pdf. Acesso em: 29 nov. 2019.

BRASIL. Ministério da Educação e do Desporto. Secretaria de Educação Fundamental. Referencial curricular nacional para a educação infantil. Brasilia, DF: MEC/SEF, 1998. Disponível em: http://portal. mec.gov.br/seb/arquivos/pdf/rcnei_voll.pdf. Acesso em: 30 nov. 2019.

BRASIL. Ministério da Educação. Programa de Apoio à Implementação da BNCC - ProBNCC. Brasília, DF: MEC, 2019. Disponivel em: http://basenacionalcomum.mec.gov.br/images/implementacao/doc_orientador_probncc_2019.pdf. Acesso em: 20 nov. 2019.

BRASIL. Ministério da Educação. Secretaria de Educação Básica. Base Nacional Comum Curricular. Documento orientador 2019. Brasília, DF: MEC/SEF, 2018. Disponível em: http://basenacionalcomum.mec. gov.br/images/implementacao/doc_orientador_probncc_2019.pdf. Acesso em: 20 nov. 2019.

BRASIL. Ministério da Educação. Secretaria de Educação Básica. Diretrizes curriculares nacionais para a educação infantil. Brasília, DF: MEC/SEF, 2010. Disponivel em: http://portal.mec.gov.br/index. php?option=com_docman\&view=download\&alias=9769-diretrizescurriculares-2012\&category_ slug=janeiro-2012-pdf\&ltemid=30192. Acesso em: 30 nov. 2019. 
BRASIL TEM 100\% de referenciais curriculares da Educação Infantil e Ensino Fundamental alinhados à BNCC. Movimento pela Base, 17 out. 2019. Disponivel em: http://movimentopelabase.org.br/acontece/ brasil-tem-100-de-referenciais-curriculares-da-educacao-infantil-e-ensino-fundamental-alinhados-bncc/. Acesso em: 20 nov. 2019.

CUNHA, E. V. R.; COSTA, H. H. C. Da expectativa de controle ao currículo como experiência em tradução. Revista Práxis Educacional, v. 15, n. 33, p. 141-163, jul./set. 2019.

DERRIDA, J. Torres de Babel. Belo Horizonte: Editora da UFMG, 2002.

DESTRO, D. S. A política curricular em Educação Física do município de Juiz de Fora - MG: hibridismo entre o contexto de produção do texto político e o contexto da prática. 2004. Dissertação (Mestrado em Educação) - Universidade do Estado do Rio de Janeiro, Rio de Janeiro, 2004.

DESTRO, D. S. Disputas políticas pela Educação Física escolar na Base Nacional Comum Curricular. 2019. Tese (Doutorado em Educação) -Universidade do Estado do Rio de Janeiro, Rio de Janeiro, 2019.

ITINERÁRIOS avaliativos auxiliam escolas na reelaboração de Projetos Políticos Pedagógicos. Educação. mg.gov.br, 19 jul. 2019. Disponivel em: http://www2.educacao.mg.gov.br/component/gmg/story/10443-itinerarios-avaliativos-auxiliam-escolas-na-reelaboracao-de-projetos-politicos-pedagogicos. Acesso em: 1 dez. 2019.

JUIZ DE FORA. Prefeitura de Juiz de Fora. Subsecretaria de Articulação das Políticas Educacionais SSAPE. Disponivel em: https://www.pjf.mg.gov.br/subsecretarias/ssape/index.php. Acesso em: 7 dez. 2019.

JUIZ DE FORA. Secretaria de Educação. A prática pedagógica na educação infantil. Diálogos no cotidiano. Juiz de Fora: [s. n., 2011. Disponivel em: https://www.pjf.mg.gov.br/secretarias/se/escolas_municipais/curriculos/arquivos/pratica_pedagogica_edinfantil.pdf. Acesso em: 6 dez. 2019.

JUIZ DE FORA. Secretaria de Educação. Departamento de Educação Infantil. Educação infantil: a construção da prática cotidiana. Juiz de Fora: [s. n., 2010. Disponível em: https://www.pjf.mg.gov.br/ secretarias/se/escolas_municipais/curriculos/arquivos/edinfantil.pdf. Acesso em: 6 dez. 2019.

JUIZ DE FORA. Secretaria Municipal de Educação. Programa Municipal de Educação Fisica. Juiz de Fora: Helvética, 2000.

LACLAU, E. Emancipação e Diferença. Rio de Janeiro: EdUERJ, 2011.

LOPES, A. C.; CUNHA, E. V. R.; COSTA, H. H. C. Da recontextualização à tradução: investigando políticas de currículo. Currículo sem Fronteiras, v. 13, n. 3, p. 392-410, set./dez. 2013.

LOPES, A. C. Currículo, política e cultura. In: SANTOS, L. L. C. P. et al. Convergências e tensões no campo da formação e do trabalho docente. Belo Horizonte: Autêntica, 2010. 
LOPES, A. C. Itinerários formativos na BNCC do Ensino Médio: identificações docentes e projetos de vida juvenis. Retratos da Escola, v. 13, n. 25, p. 59-75, jan./maio 2019.

LOPES, A. C.; MACEDO, E. Teorias de Currículo. São Paulo: Cortez, 2011.

LOPES, A. C. Normatividade e intervenção política: em defesa de um investimento radical. In: LOPES, A. C.; MENDONÇA, D. A teoria do discurso de Ernesto Laclau: ensaios e entrevistas. São Paulo: Annablueme, 2015.

LOPES, A. C. Política, conhecimento e a defesa de um vazio normativo. In: MENDONÇA, D.; RODRIGUES, L; LINHARES, B. (org.). Ernesto Laclau e seu legado transdisciplinar. São Paulo: Intermeios, 2017.

MACEDO, E. F. Fazendo a Base virar realidade: competências e o germe da comparação. Retratos da Escola, v. 13, n. 25, p. 39-58, jan./maio 2019.

RIBEIRO, W. G.; CRAVEIRO, C. B. Precisamos de uma Base Nacional Comum Curricular? Linhas Críticas, v. 23, n. 50, p. 51-69, fev./maio 2017.

SISCAR, M. Jacques Derrida: literatura, política e tradução. Campinas: Autores Associados, 2012.

STRATHERN, P. Derrida em 90 minutos. Rio de Janeiro: Jorge Zahar Ed., 2002.

Endereço para correspondência: Avenida Garibaldi Campinhos, n. 112/402, Vitorino Braga, 36060-140, Juiz de Fora, Minas Gerais, Brasil; denisesdestro@gmail.com 